\title{
Skeletonized coronary arteries: pathophysiological and clinical aspects of vascular calcification
}

\author{
This article was published in the following Dove Press journal: \\ Vascular Health and Risk Management \\ 8 March 201I \\ Number of times this article has been viewed
}

\author{
Carlos V Serrano Jr' \\ Marcelo Oranges ${ }^{2}$ \\ Vitor Brunaldi² \\ Alexandre de M Soeiro' \\ Tatiana Andreucci Torres' \\ José Carlos Nicolau' \\ José Antonio F Ramires' \\ 'Heart Institute, ${ }^{2}$ Medical School, \\ University of São Paulo, Brazil
}

Correspondence: Carlos V Serrano Jr Heart Institute, Av Enéas de C Aguiar, 44 Building II, 2nd Floor, Room I2, São Paulo, SP 05403-000, Brazil Tel +55 II 30695058

Fax +55 । I 30883809

Email carlos.serrano@incor.usp.br

\begin{abstract}
The role of calcification in coronary artery disease is gaining importance, both in research studies and in clinical application. Calcified plaque has long been considered to be the most important atherosclerotic plaque within the arterial tree and frequently presents a challenge for percutaneous intervention. Current investigations have shown that plaque calcification has a dynamic course that is closely related to the magnitude of vascular inflammation. Numerous inflammatory factors synthesized during the early stages of atherosclerosis induce the expression and activation of osteoblast-like cells localized in the arterial wall that produce calcium. There is no doubt that the role of these factors in calcification associated with coronary artery disease could be a crucial strategic point in prevention and treatment. A number of diagnostic imaging methods have been developed in recent years, but their performance needs to be improved. In this context, we undertook an update on coronary calcification, focusing on physiopathology, clinical implications, and imaging techniques.
\end{abstract}

Keywords: vascular smooth muscle cells, atherosclerotic plaques, vascular calcification

\section{Introduction}

The role of "skeletonization", referred to as calcification, in the development of coronary artery disease is gaining importance, both in research and in clinical application. Calcified plaque has long been recognized as the most important atherosclerotic plaque within the arterial tree, ${ }^{1}$ and frequently presents a challenge for percutaneous intervention. ${ }^{2}$ Current investigations have shown that plaque calcification has a dynamic course that is closely related to the magnitude of vascular inflammation. ${ }^{3}$ Numerous inflammatory factors synthesized during the early stages of atherosclerosis induce the expression and activation of osteoblast-like cells localized in the arterial wall that produce calcium. ${ }^{4,5}$

In approximately $15 \%$ of human atherosclerotic plaques, calcium precipitation develops a complete skeletal architecture, histologically indistinguishable from trabecular bone, even including marrow and cartilage. ${ }^{6}$

It is now understood that microcalcification deposits in the borders of atherosclerotic plaque are related to increased risk for plaque instability and fibrous cap rupture, followed by coronary thrombus formation and adverse clinical events. ${ }^{7}$ Thus, the perception that calcified plaques are less vulnerable to rupture has been adapted in order to investigate the characteristics of calcification, such as extent, location, and morphology. ${ }^{7}$

Calcium deposits may be found at many sites in the cardiovascular tree, including in the medial layer of the large arteries (medial arterial calcification), within atherosclerotic plaque (intimal calcification), on cardiac valves, particularly mitral and aortic, 
and in the microvessels (calcific uremic arteriolopathy). ${ }^{8}$ Calcium deposition at these different sites follows different clinical courses, and they each seem to have at least some distinct pathophysiologic features.

\section{Osteogenic induction}

Vascular smooth muscle cells have an extraordinary capacity to undergo phenotypic differentiation. This depends on media status, injury factors, and their influence on specific transcription factors. Such phenotypic changes may be very important in the pathological process, and might even be their key factor. ${ }^{9}$

Cbfa1, Msx2, and Sox9 are identified as the master regulators of bone and cartilage differentiation. ${ }^{10-12}$ These are responsible for the regulation of several genes related to osteocytic/chondrocytic differentiation in vascular smooth muscle cells. Tyson et $\mathrm{al}^{13}$ could not detect expression of these regulatory factors in freshly dispersed normal vascular smooth muscle cells by reverse transcription polymerase chain reaction. However, in vitro, phenotypically modified calcifying vascular smooth muscle cells activate different transcriptional pathways, associated with variation in expression of these master regulators and their target genes. ${ }^{13}$

Several stimuli may induce vascular smooth muscle cells to undergo osteogenic differentiation. Oxidative stress, defective phosphate and calcium production, and lack of calcification inhibitors, among other factors, will be discussed in order to explain osteogenic induction. ${ }^{13}$

\section{Agonists of the osteochondrogenic phenotype}

Byon et $\mathrm{al}^{14}$ demonstrated the very important role of oxidative stress in osteogenic differentiation in vascular smooth muscle cells. $\mathrm{H}_{2} \mathrm{O}_{2}$ promotes the specific phenotypic change associated with increased expression and transactivity of Runx2, a key transcription factor for osteogenic differentiation. Real-time polymerase chain reaction performed in $\mathrm{H}_{2} \mathrm{O}_{2}-$ treated cultures showed a significant increase in the expression of bone markers, whereas the expression of vascular smooth muscle cell markers decreased gradually during osteogenic differentiation of vascular smooth muscle cells undergoing $\mathrm{H}_{2} \mathrm{O}_{2}$ treatment. ${ }^{14}$

Lipoproteins, like native low-density lipoprotein and acetylated low-density lipoprotein, influence the expression of a subset of bone marker genes, like alkaline phosphatase and bone sialoprotein, in vascular smooth muscle cells in vitro and have an important role in vascular calcification. Proudfoot et $\mathrm{al}^{15}$ demonstrated this in a model of vascular smooth muscle cell calcification in which postconfluent vascular smooth muscle cells formed nodules that calcified within 28 days. ${ }^{15}$

\section{Loss of inhibition}

Fetuin-A, also known as (alpha2)-Heremens-Schmid glycoprotein, is a protein made in the liver and secreted into the blood stream. It belongs to a large group of binding proteins mediating the transport and availability of a wide variety of cargo substances in the blood. Reynolds et $\mathrm{al}^{16}$ demonstrated that mice lacking fetuin-A exhibit extensive soft tissue calcification, suggesting that fetuin-A inhibits calcification systemically. Uptake of fetuin-A by vascular smooth muscle cells is a key event in the inhibition of vesicle-mediated vascular smooth muscle cell calcification. Fetuin-A is barely detectable in the media or intima of noncalcified normal arteries by immunohistochemistry. However, fetuin-A staining is present in calcified medial and intimal areas of arteries, both deposited in association with vascular smooth muscle cells and the matrix. Vascular smooth muscle cells within calcified regions are strongly positive for fetuin-A. Reverse transcription polymerase chain reaction in normal and calcified arteries cannot detect fetuin-A mRNA, indicating that it is not synthesized by vascular smooth muscle cells, but derived from the serum. Fetuin-A inhibits vascular smooth muscle cell calcification induced by media containing calcium and phosphate ions. Fetuin-A is a binder of basic calcium phosphate and an inhibitor of spontaneous precipitation of calcium and phosphate in solution. In the presence of vascular smooth muscle cells, the inhibitory capacity of fetuin-A is significantly increased, suggesting that it also acts via cellmediated mechanisms. ${ }^{16}$ Apoptosis contributes to vascular smooth muscle cell calcification induced by calcium and phosphate ions in serum-free conditions. Immunofluorescent TUNEL labeling shows that apoptosis induced in response to medium containing calcium and phosphate ions was significantly reduced by $5 \mu \mathrm{M}$ fetuin-A. Fetuin-A reduces apoptotic events by approximately half over a 48-hour time course, and this is associated with reduced cleavage of caspases 3, 8, and 9. Matrix vesicles that are released from vascular smooth muscle cells cultured in the presence of fetuin-A do not calcify. In contrast, matrix vesicles released from vascular smooth muscle cells in the absence of fetuin-A calcify extensively. Fetuin-A is taken up by vascular smooth muscle cells and loaded into intracellular vesicles, where it prevents nucleation of basic calcium phosphate. It also enhances the potential for apoptotic body clearance and limits their capacity to bind and nucleate basic 
calcium phosphate in the extracellular matrix. The potential role of fetuin-A in regulating the osteoblastic phenotype of vascular smooth muscle cells should be investigated. ${ }^{16}$

\section{Additional factors that modulate bone formation \\ Reactive oxygen species}

The contribution of oxidative stress and vascular calcification may provide a link between inflammation and vascular calcification, which are both conditions present in atherosclerotic plaque. Interestingly, calcific vasculopathy may be a compensatory response to the chronic inflammation of atherosclerosis, because it occurs in calcification surrounding tuberculoma, carcinomas, helminthic infections, or foreign body inclusions. ${ }^{17}$

Reactive oxygen species signaling can induce markers of osteoblastic differentiation, including bone morphogenic protein-2 (BMP2) and Cbfa1. Under oxidative stress conditions, certain subpopulations of cardiovascular cells can develop a capacity for osteogenesis. Endothelial cells, when exposed to oxidized low-density lipoprotein, express BMP2. ${ }^{18}$ BMP2 induces cyclo-oxygenase-2 mRNA expression and prostaglandin production in cultured osteoblasts. ${ }^{19}$ In addition, in endothelial cells, BMP2 increases expression of nicotinamide adenine dinucleotide phosphate oxidase, thereby increasing superoxide formation. In addition, BMP2 in the endothelium induces intercellular adhesion molecule-1 expression, facilitating the adhesive interactions with circulating monocytes. ${ }^{19}$

\section{Alkaline phosphatase}

Alkaline phosphatase, a functional phenotype marker of osteoblasts, modulates vascular calcification by decreasing levels of inorganic pyrophosphate. ${ }^{20}$ Pyrophosphate is a potent inhibitor of calcification, particularly in vessel walls. Alkaline phosphatase activity is often used as a molecular marker for osteogenic and chondrogenic differentiation. Accordingly, smooth muscle cells undergoing medial calcification express higher levels of alkaline phosphatase, and the classic stimuli of atherosclerotic vascular calcification, including BMP2 and oxidized low-density lipoprotein, increase alkaline phosphatase activity in cultured vascular smooth muscle cells. ${ }^{21}$

\section{Leptin}

Serum leptin levels may contribute to vascular calcification. Leptin levels are associated with both visceral obesity and renal failure (as a consequence of reduced leptin filtration). ${ }^{22}$
In addition, there is evidence that leptin may selectively modulate vascular smooth muscle cells to undergo osteoblastic differentiation. ${ }^{23}$ In aortic endothelial cells, leptin increases oxidative stress, which has been shown to increases BMP2 production by these cells. ${ }^{24}$

\section{Apoptosis}

Exaggerated apoptosis of vascular smooth muscle cells occurs in several pathological conditions and as a normal consequence of aging. Apoptotic bodies of dead foam cells and smooth muscle cell debris, in addition to matrix vesicles derived from viable smooth muscle cells and calcific vascular cells, may serve to concentrate calcium and phosphate locally. ${ }^{25}$ Apoptosis, in part, can explain the medial calcification common in the elderly.

\section{Coronary artery calcification in end-stage renal disease}

Cardiovascular disease is the primary cause of mortality among adults with chronic renal disease, with a 10-20-fold higher mortality rate compared with the general population without renal function impairment. ${ }^{26}$ It has become apparent that vascular calcification is a strong prognostic marker of cardiovascular disease mortality in patients with chronic renal disease, ${ }^{27,28}$ even amongst children with end-stage kidney disease. ${ }^{29}$

The pathogenesis of vascular calcification in chronic renal disease is not well understood. Vascular calcification has long been considered to be a passive, degenerative, and endstage process of atherosclerosis and inflammation. At the present time, numerous factors have been identified to participate in the formation of vascular calcification in chronic renal disease. ${ }^{30}$ In patients with chronic renal disease, several studies have found associations between both traditional risk factors, such as hypertension, hyperlipidemia, and diabetes, and uremic-specific risk factors for vascular calcification. These latter factors consist of hyperphosphatemia and calcium-regulating hormones. ${ }^{30}$

Most patients with progressive chronic renal disease develop hyperphosphatemia, which mediates matrix mineralization in vascular smooth muscle cells. ${ }^{31}$ Elevated phosphate may directly stimulate smooth muscle cells to undergo phenotypic changes that predispose to calcification. ${ }^{32}$

Contemporary understanding suggests that bone matrix proteins such as osteopontin, matrix Gla protein, and osteocalcin are expressed in calcified atherosclerotic lesions, and that calcium-regulating hormones, such as vitamin $\mathrm{D}_{3}$ and parathyroid hormone-related protein, regulate vascular calcification in in vitro vascular calcification models based 
on cultured aortic smooth muscle cells. These findings suggest that vascular calcification is an actively regulated process similar to osteogenesis, and that bone-associated proteins may be involved in the development of vascular calcification. ${ }^{32}$

Calcitriol is indicated in patients with chronic renal disease in order to avoid secondary hyperparathyroidism related to impaired ability of the ailing kidney to convert vitamin D into its active form, $1,25(\mathrm{OH})_{2} \mathrm{D}_{3}$. Calcitriol elevates serum calcium levels and inhibits parathyroid hormone secretion. However, although this therapy aims to prevent secondary hyperparathyroidism, the consequent increase in serum calcium levels, together with increased serum phosphate, may inadvertently induce mineralization in the vasculature. Therefore, the recommendation for vitamin D intake must be made with caution due to its role in vascular calcification. ${ }^{32}$

\section{Role of high-density lipoprotein in vascular calcification}

High-density lipoprotein may inhibit vascular calcification by modulating the osteogenic activity of calcifying vascular cells. Parhami et al ${ }^{33}$ treated calcifying vascular cells with high-density lipoprotein and noted that alkaline phosphatase activity, a marker of osteogenic differentiation of osteoblastic cells, was markedly affected in those cells. In addition, chronic treatment with high-density lipoprotein also inhibited calcification of the cells. Furthermore, high-density lipoprotein inhibited the osteogenic activity induced by the inflammatory cytokines, interleukin-1 and interleukin-6, as did minimally oxidized low-density lipoprotein ${ }^{33}$ (see Figures 1 and 2).

\section{Categories of vascular calcification}

Categories of cardiovascular calcification have been identified clinically, ie, atherosclerotic or intimal calcification, medial artery calcification, vascular calciphylaxis, and cardiac valve calcification. ${ }^{34}$ Vascular calcification occurs in both the intimal and the medial layers of the arteries. However, there is evidence to suggest that these two sites of calcification are distinct entities, but can occur simultaneously and synergistically aggravate artery burden. ${ }^{34}$

\section{Atherosclerotic calcification}

Intimal calcification only occurs within atherosclerotic plaques, and is seen as early as the second decade of life, just after the fatty streak is formed. ${ }^{35}$ This stage of cellular events is characterized by oxidation of low-density lipoprotein cholesterol, recruitment of T cells, and activation of macrophages. The process of "skeletonization" is initially developed through endochondrial ossification which,
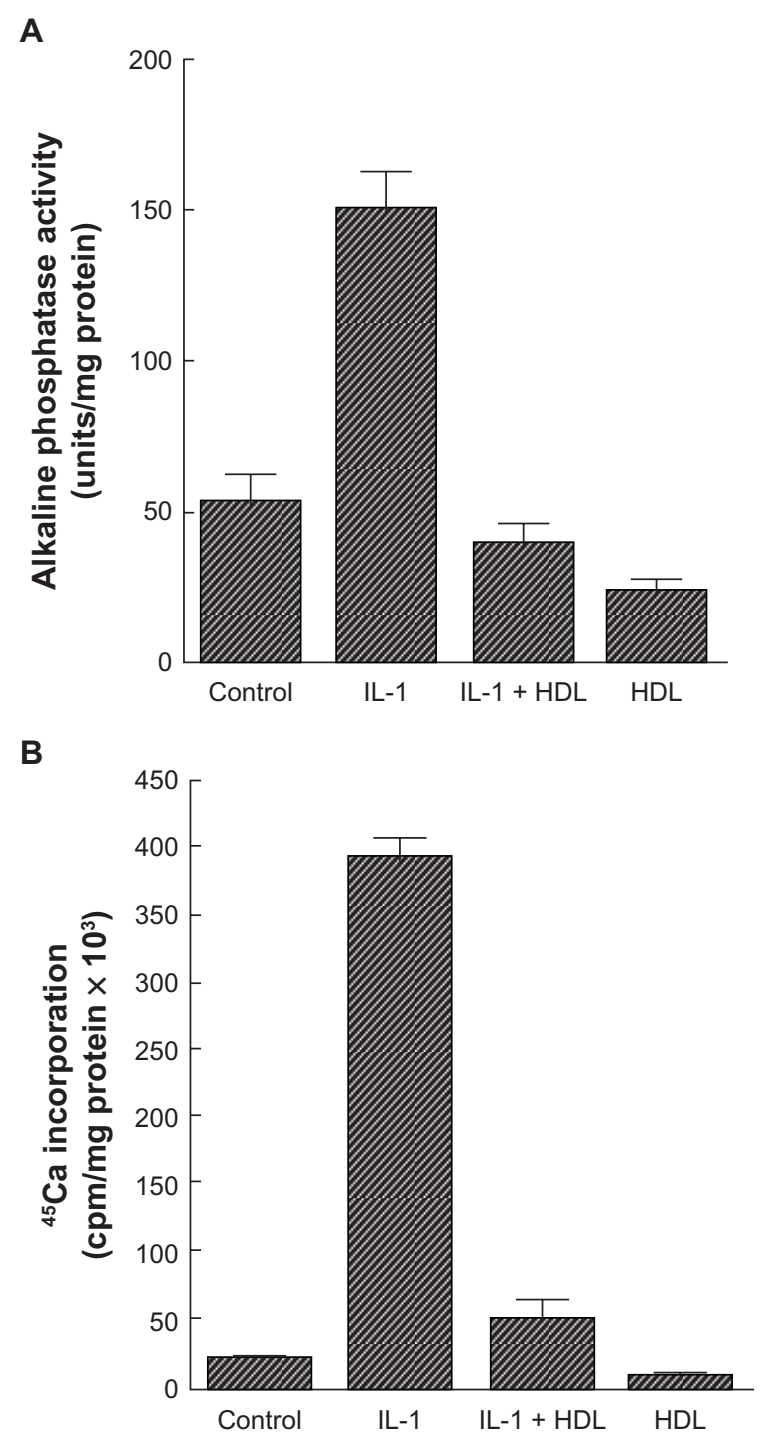

Figure I Effect of high-density lipoprotein on cardiovascular cell responses to interleukin- I.A) Cardiovascular cell cultures were pretreated for 24 hours with highdensity lipoprotein $(200 \mu \mathrm{g} / \mathrm{mL})$ in Dulbecco's Modified Eagle Medium containing 5\% fetal bovine serum, followed by the addition of fresh high-density lipoprotein with or without interleukin-I (10 ng/mL). After two days, alkaline phosphatase activity was measured as previously described. Results from a representative of three experiments are shown as mean \pm standard deviation of quadruple determinations. $P<0.005$ for untreated control versus interleukin-I-treated samples, for interleukin-I- versus interleukin-I + high-density lipoprotein-treated samples, and for untreated control versus high-density lipoprotein-treated samples. B) Cells were treated as described above. After 10 days, a ${ }^{45} \mathrm{Ca}$ incorporation assay was performed. Results from a representative of three experiments are shown as mean \pm standard deviation of quadruple determinations. $P<0.005$ for untreated control versus interleukin-Itreated samples and for interleukin- I- versus interleukin- I + high-density lipoproteintreated samples. Adapted from Parhami et al. ${ }^{33}$

in turn, precedes osteoblast induction and lamellar bone formation. As the lesion progresses, osteogenesis is apparent and is occasionally quite complex, inclusively with marrow formation. ${ }^{36}$ Importantly, bone-related proteins are present as early as the intimal xanthoma stage of lesion progression, and histological evidence of calcification is visible once a lipid core is outlined. ${ }^{37}$ 
A

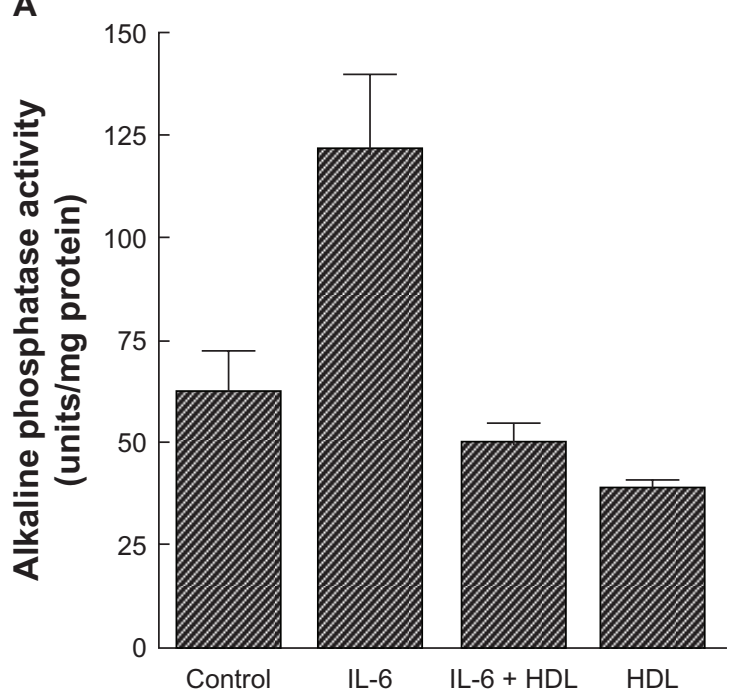

B

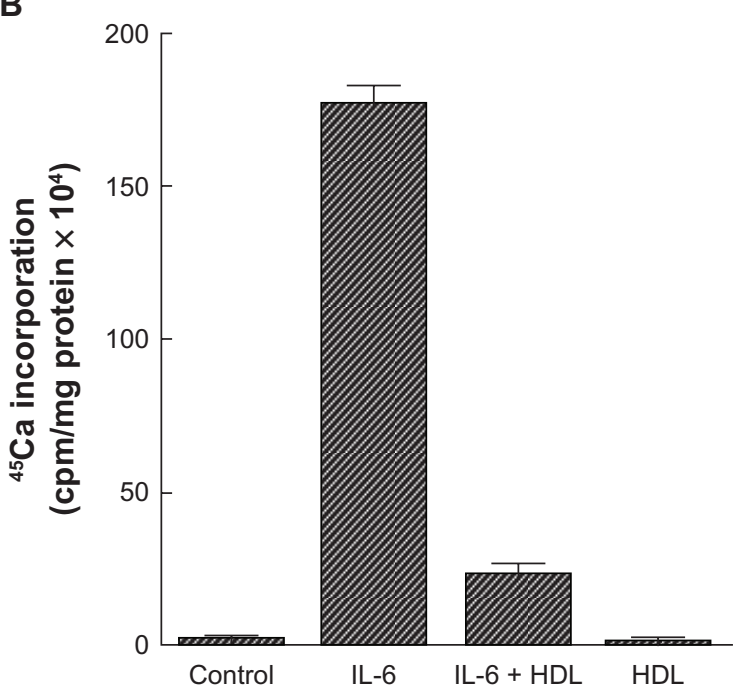

Figure 2 Effect of high-density lipoprotein on cardiovascular cell responses to interleukin-6. A) Cardiovascular cell cultures were pretreated for 24 hours with high-density lipoprotein $(200 \mu \mathrm{g} / \mathrm{mL})$ in Dulbecco's Modified Eagle Medium containing $5 \%$ fetal bovine serum, followed by the addition of fresh high-density lipoprotein with or without interleukin-6 $(50 \mathrm{ng} / \mathrm{mL})$. After four days, alkaline phosphatase activity was measured as previously described. Results from a representative of three experiments are shown as mean \pm standard deviation of quadruple determinations. $P<0.001$ for control versus interleukin-6-treated samples and for interleukin-6versus interleukin- 6 + high-density lipoprotein-treated samples; $P<0.05$ for control versus high-density lipoprotein-treated samples. B) Cells were treated as described above. After 10 days, a ${ }^{45} \mathrm{Ca}$ incorporation assay was performed. Results from three representative experiments are shown as mean \pm standard deviation of quadruple determinations. $P<0.001$ for control versus interleukin-6-treated samples and for interleukin-6- versus interleukin-6 + high-density lipoprotein-treated samples. Adapted from Parhami et al. ${ }^{33}$

The role of calcification in the process of atherosclerotic plaque rupture is unclear. Research studies have demonstrated that plaque may rupture due to physical stress exerted at sites of calcification on the fibrous cap and is biphasic and dose-dependent, based on mechanical stress considerations. Plaque calcification initially destabilizes a plaque, specifically at the areas of interface between hard and soft tissues..$^{38}$
As the degree of calcification increases, the number of interfaces between rigid and distensible plaque initially would increase until the point at which the rigid plaques coalesce (Figure 3). Further calcification would result in a decreased interface area and reducing the chances of rupture. ${ }^{39} \mathrm{On}$ the other hand, other investigations have suggested that calcified plaques are more stable and less prone to rupture. ${ }^{40}$

In addition, focal calcification strongly favors arterial dissection during coronary interventions, such as angioplasty and stent placement. ${ }^{41}$ Angioplasty to extensively calcified lesions in particular carries an increased risk, even in the stent and glycoprotein IIb/IIIa era, because of higher failure and complication rates. Calcified lesions are stiff and resistant to adequate dilatation, leading to increased risk of vessel closure from dissections originating at the junction of the calcified and noncalcified regions of the plaque. In addition, the high inflation pressures required increase the risk of balloon rupture and even vessel perforation. Rotational atherectomy has been shown to increase success and to reduce the complication rate in calcified lesions, but the restenosis rate remains unchanged. ${ }^{42}$

Stenting of highly calcified lesions is also problematic because of lack of full stent expansion and difficulty in delivery to the target site. Several studies have shown improved results by using rotational atherectomy to debulk the calcium before stent placement. These studies showed appropriate stent expansion in most cases, and a reduced restenosis rate compared with rotational atherectomy followed by angioplasty alone. ${ }^{43}$

\section{Medial artery calcification}

On the other hand, medial calcification occurs independently of intimal calcification and atherosclerosis. Metabolic disorders, such as uremia, hyperparathyroidism, and diabetes,

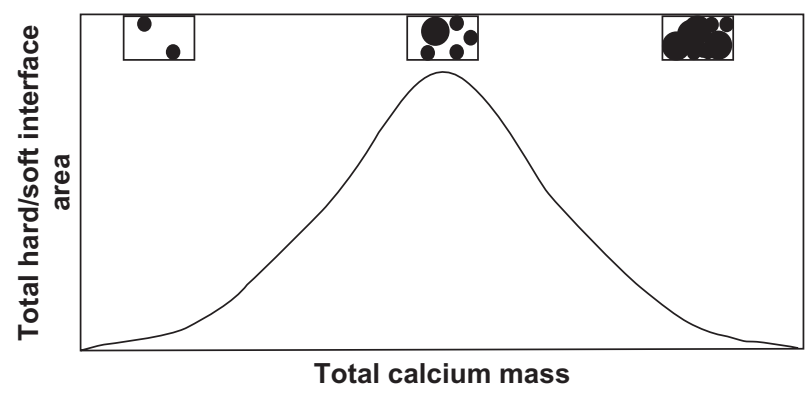

Figure 3 Relationship between plaque interface area versus total calcium mass. Biomechanical principles suggest the risk of plaque rupture should correlate with the interface area, which eventually decreases as calcified plaques begin to coalesce. The corresponding figure insets illustrate how the interface (the circumference around the black area) eventually decreases as calcified areas continue to form and grow. Adapted from Abedin et al. ${ }^{2}$ 
are associated with development of medial calcification that occurs even in areas without adjacent atherosclerosis. ${ }^{44}$

Medial calcification is more likely to be present in the peripheral arteries of the lower limbs in otherwise healthy elderly patients (Monckeberg's sclerosis), where it is seen as "rail tracking" on plain radiographs. However, it also occurs in younger patients with diabetes and in patients with chronic renal failure. In diabetic patients, medial calcification appears to be a strong independent predictor of cardiovascular mortality and occurs particularly in those with neuropathy. ${ }^{44}$ Specifically within diabetic patients, medial calcification is a result of migration of procontractile adventitial myofibroblasts into the medial layer and, subsequently, transformation to an osteoblastic phenotype when vascular cell smooth muscle cells express osteopontin. ${ }^{44}$

In terms of clinical importance, medial calcification is a risk factor for arterial stiffness. This phenomenon results in difficulties in palpating pulses and hearing Korotkoff sounds, leading to false elevation of systolic blood pressure measurements. ${ }^{44}$ Another complication related to vascular stiffness is the onset of left ventricular hypertrophy (due to increases in pulse-wave velocity and systolic blood pressure, and to a decrease in diastolic blood pressure). ${ }^{45}$ It also causes problems with the surgical management of vascular shunts. Further investigations are necessary to distinguish between superficial, focal atherosclerotic calcification and deep, concentric medial calcification and risk of plaque rupture.

\section{Calciphylaxis}

A very rare phenomenon, vascular calciphylaxis, or calcific uremic arteriolopathy, occurs in approximately $1 \%$ of patients on hemodialysis. This vascular condition is a systemic process involving diffuse calcification of the media of small-sized to medium-sized arteries and arterioles with intimal proliferation leading to tissue necrosis, such as in skin, muscle, and fat. ${ }^{46}$

Calciphylaxis is not dependent on active osteogenesis and, in patients with chronic renal disease or secondary hyperparathyroidism, can be preceded by either extensive use of warfarin or by significant weight loss. It has also been related to immunosuppressive agents, diabetes, obesity, and hypercoagulable states. Calciphylaxis has a mortality rate of $60 \%-80 \% .{ }^{46}$

\section{Imaging techniques to visualize coronary "skeletonization"}

A diversity of imaging modalities is accessible to detect arterial calcification, including roentgenography, echocardiography, intravascular ultrasound, and computerized tomography. These modalities differ both in sensitivity and specificity, as well as clinical relevance. ${ }^{46}$

\section{Chest roentgenography and echocardiography}

Chest radiography is a weak tool for detecting vascular calcification. Widespread, extensive calcification can be visualized through radiograms in the aorta, which could suggest concomitant coronary damage. A similar rationale also occurs with the use of echocardiography where valvular calcification can be easily diagnosed (Figure 4). ${ }^{46}$

\section{Intravascular ultrasound}

This modality serves to identify sites of calcification within the different components of the artery wall (intima, media and adventitia) and within plaques. Intravascular ultrasound has both high specificity and sensitivity for calcified areas, as it appears hyperechoic (Figure 5). ${ }^{47} \mathrm{~A}$ drawback of intravascular ultrasound is the fact that it is an invasive, nonquantitative procedure and visualizes only a limited portion of the coronary artery circulation. However, it is a very useful instrument for the interventional cardiologist because it can identify areas with localized calcification, specifically those areas at risk for dissection. ${ }^{48,49}$

\section{Computed tomography}

Necropsy studies have demonstrated that the amount of intimal calcium in the coronary arteries is related closely to the amount of plaque. In other words, where there is calcification there is usually plaque, and where there is plaque there is usually calcification. ${ }^{50}$ Computed tomography (CT) has become known as a noninvasive, sensitive method to detect and measure coronary calcification and stenosis. Two major CT methods used to evaluate and assess plaque burden,

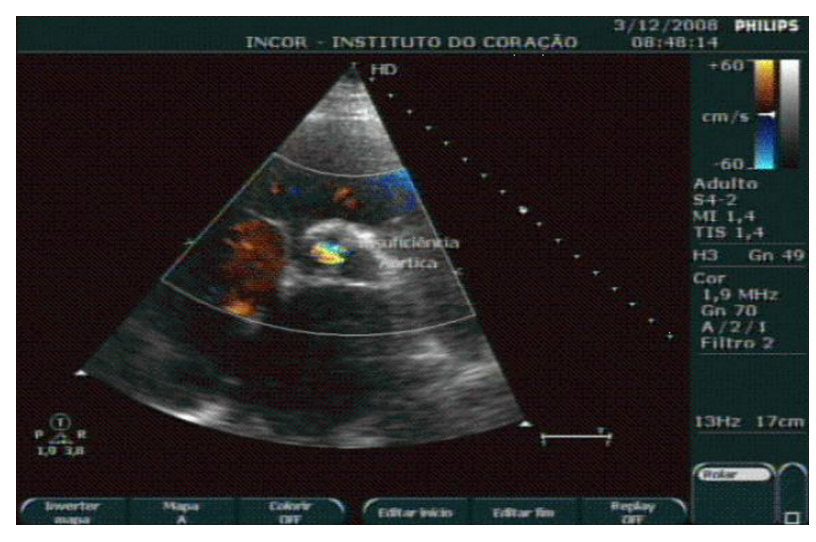

Figure 4 Echocardiography image showing calcified aortic valve. 


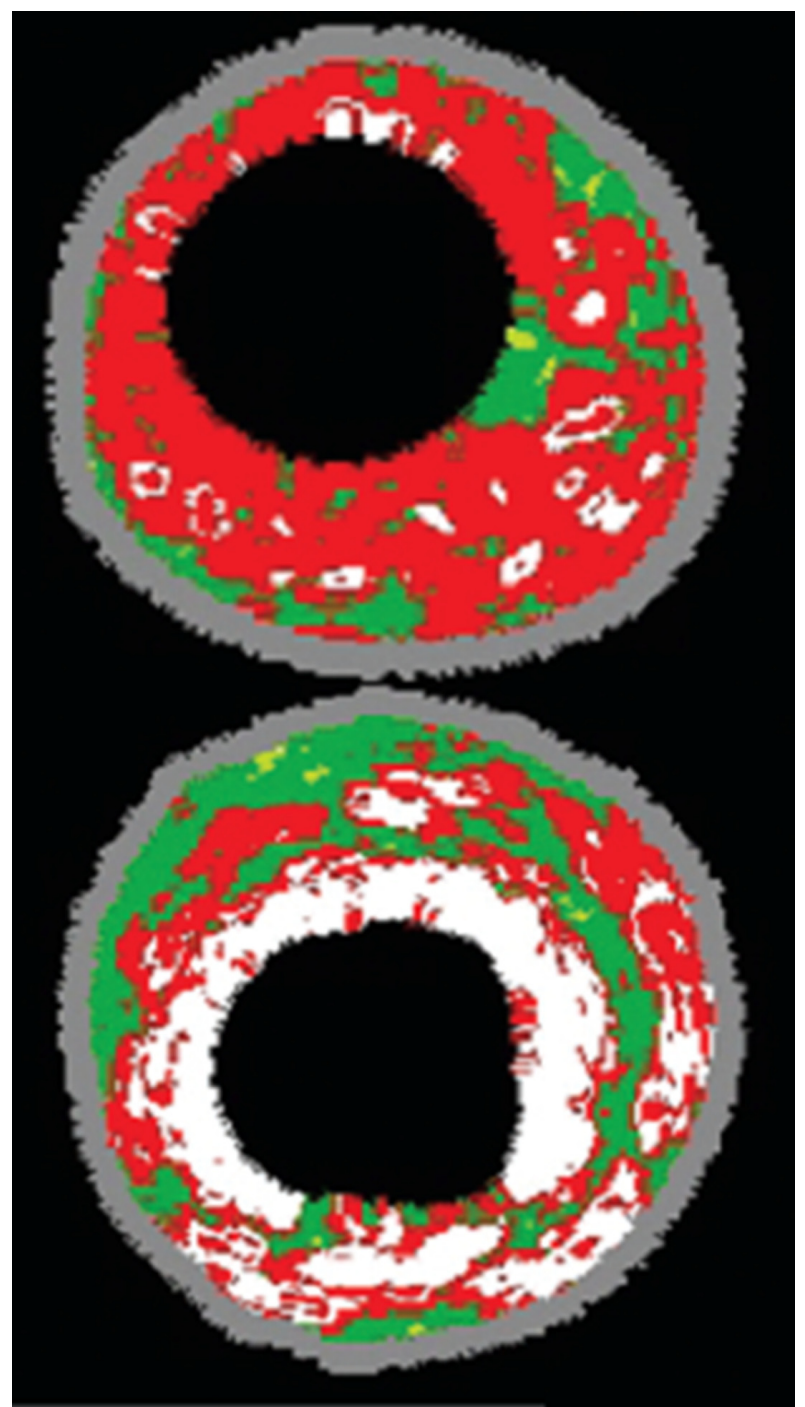

Figure 5 Intravascular ultrasound image showing necrotic core in a thin-cap fibroatheroma lesion appearing as red (top) and dense calcium in fibrocalcific disease appearing as white (bottom). Adapted from Murray et al. ${ }^{49}$

composition, and extension, mainly regarding coronary heart disease will be discussed, ie, CT coronary angiography and the use of the standardized Agatston scoring system in order to create coronary artery calcium scores. Using coronary artery calcium scores, CT imaging permits quantification of artery calcification (Figure 6). ${ }^{51,52}$ Many studies have compared information on $\mathrm{CT}$ and coronary artery calcium scores, and most of them have concluded that information from each of these examinations is very helpful to the other. ${ }^{53}$ Coronary artery calcium scoring is considered to improve the prediction of the presence of obstructive coronary artery disease independent of clinical predictors. ${ }^{54}$ Meantime, multislice CT coronary angiography has been shown to provide additional information regarding stenosis severity and plaque composition, which translates into incremental
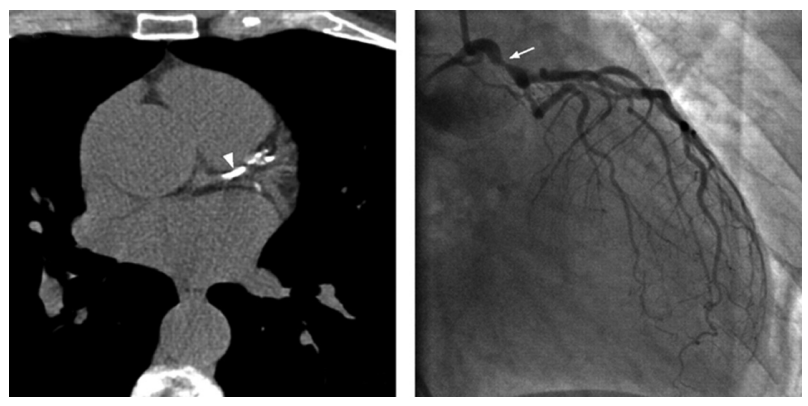

Figure 6 Computed tomographic image showing coronary calcification not shown in the same lesion on coronary angiography. Adapted from Mittal et al. ${ }^{52}$

prognostic value over coronary artery calcium scores. ${ }^{55}$ Furthermore, an interesting study compared evaluation of the atheroma burden with CT coronary angiography and coronary artery calcium scores in patients at significant risk for coronary artery disease, such as age and diabetes. The conclusion was that CT coronary angiography was superior in determining the atheroma burden in this group of patients. ${ }^{56}$ Despite the comparison between CT coronary angiography and coronary artery calcium scoring, an increasing amount of evidence has consistently shown increased coronary artery calcium scores to be positively correlated with atherosclerotic plaque burden. ${ }^{57}$ In diabetic patients, coronary artery calcium scoring may be a useful follow-up examination once it has been demonstrated that every increase in coronary artery calcium score is strongly correlated with a greater increase in mortality. ${ }^{58}$ The coronary artery calcium score may be a complementary risk factor to traditional cardiovascular stratification factors. ${ }^{59}$ A positive correlation between coronary calcium score and subsequent clinical events in patients with known coronary artery disease has been documented. ${ }^{57}$ On the other hand, a coronary artery calcium score of zero has a negative predictive value of about $95 \%$ for important epicardial coronary artery stenosis. ${ }^{60}$ As a screening tool for obstructive coronary artery disease, coronary artery calcium scoring is not recommended for low-risk populations due to its low specificity and a high false positive rate, although its selective use in patients at intermediate risk may be appropriate. $^{61}$

\section{Conclusion}

There is no doubt that the role of calcification in coronary artery disease could be a crucial strategic point in prevention and treatment. However, we are only at the beginning of our understanding of this topic, and so many studies are necessary to clarify the complete physiopathology and perhaps help in prevention. Different diagnostic imaging methods 
have been developed in recent years, but their performance needs to be improved.

\section{Disclosure}

The authors report no conflict of interest in this work.

\section{References}

1. Frink RJ, Achor RW, Brown AL Jr, Kincaid OW, Brandenburg RO. Significance of calcification of the coronary arteries. Am J Cardiol. 1970;26:241-247.

2. Moses JW, Carlier S, Moussa I. Lesion preparation prior to stenting. Rev Cardiovasc Med. 2004;5 Suppl 2:S16-S21.

3. Abedin M, Tintut Y, Demer LL. Vascular calcification: Mechanisms and clinical ramifications. Arterioscler Thromb Vasc Biol. 2004;24: $1161-1170$

4. Dhore CR, Cleutjens JP, Lutgens E, et al. Differential expression of bone matrix regulatory proteins in human atherosclerotic plaques. Arterioscler Thromb Vasc Biol. 2001;21:1998-2003.

5. Shanahan CM, Cary NR, Metcalfe JC, Weissberg PL. High expression of genes for calcification-regulating proteins in human atherosclerotic plaques. J Clin Invest. 1994;93:2393-2402.

6. Mohler ER 3rd, Gannon F, Reynolds C, Zimmerman R, Keane MG, Kaplan FS. Bone formation and inflammation in cardiac valves. Circulation. 2001;103:1522-1528.

7. Serrano CV Jr, Rocha Giraldez R, Fernandes JL, Nicolau JC, Zweier JL, Ramires JA. Platelet and leukocyte adhesion and activation in unstable angina and post-PTCA. Int J Cardiol. 2005;99:423-428.

8. Caira FC, Stock SR, Gleason TG, et al. Human degenerative valve disease is associated with up-regulation of low-density lipoprotein receptor-related protein 5 receptor-mediated bone formation. $\mathrm{J} \mathrm{Am} \mathrm{Coll}$ Cardiol. 2006;47:1707-1712.

9. Iyemere VP, Proudfoot D, Weissberg PL, Shanahan CM. Vascular smooth muscle cell phenotypic plasticity and the regulation of vascular calcification. J Intern Med. 2006;260:192-210.

10. Komori T, Yagi H, Nomura S, et al. Targeted disruption of Cbfa1 results in a complete lack of bone formation owing to maturational arrest of osteoblasts. Cell. 1997;89:755-764.

11. Bi W, Deng JM, Zhang Z, Behringer RR, de Crombrugghe B. Sox9 is required for cartilage formation. Nat Genet.1999;22:85-89.

12. Wilkie AO, Tang Z, Elanko N, et al. Functional haploinsufficiency of the human homeobox gene MSX2 causes defects in skull ossification. Nat Genet. 2000;24:387-390.

13. Tyson KL, Reynolds JL, McNair R, Zhang Q, Weissberg PL, Shanahan CM. Osteo/chondrocytic transcription factors and their target genes exhibit distinct patterns of expression in human arterial calcification. Arterioscler Thromb Vasc Biol. 2003;23:489-494.

14. Byon CH, Javed A, Dai Q, et al. Oxidative stress induces vascular calcification through modulation of the osteogenic transcription factor Runx2 by AKT signaling. J Biol Chem. 2008;283:15319-15327.

15. Proudfoot D, Davies JD, Skepper JN, Weissberg PL, Shanahan CM. Acetylated low-density lipoprotein stimulates human vascular smooth muscle cell calcification by promoting osteoblastic differentiation and inhibiting phagocytosis. Circulation. 2002;106:3044-3050.

16. Reynolds JL, Skepper JN, McNair R, et al. Multifunctional roles for serum protein fetuin-a in inhibition of human vascular smooth muscle cell calcification. J Am Soc Nephrol. 2005;16:2920-2930.

17. Johnson RC, Leopold JA, Loscalzo J. Vascular calcification: Pathobiological mechanisms and clinical implications. Circ Res. 2006; 99:1044-1059.

18. Cola C, Almeida M, Li D, Romeo F, Mehta JL. Regulatory role of endothelium in the expression of genes affecting arterial calcification. Biochem Biophys Res Commun. 2004;320:424-427.
19. Chikazu D, Li X, Kawaguchi H, et al. Bone morphogenetic protein 2 induces cyclo-oxygenase 2 in osteoblasts via a Cbfa 1 binding site: Role in effects of bone morphogenetic protein 2 in vitro and in vivo. J Bone Miner Res. 2005;20:1888-1898.

20. Jono S, McKee MD, Murry CE, et al. Phosphate regulation of vascular smooth muscle cell calcification. Circ Res. 2000;87:E10-E17.

21. Lomashvili KA, Cobbs S, Hennigar RA, Hardcastle KI, O'Neill WC. Phosphate-induced vascular calcification: Role of pyrophosphate and osteopontin. J Am Soc Nephrol. 2004;15:1392-1401.

22. Takeda S, Elefteriou F, Levasseur R, et al. Leptin regulates bone formation via the sympathetic nervous system. Cell. 2002;111:305-317.

23. Parhami F, Tintut Y, Ballard A, Fogelman AM, Demer LL. Leptin enhances the calcification of vascular cells: Artery wall as a target of leptin. Circ Res. 2001;88:954-960.

24. Yamagishi SI, Edelstein D, Du XL, Kaneda Y, Guzman M, Brownlee M. Leptin induces mitochondrial superoxide production and monocyte chemoattractant protein-1 expression in aortic endothelial cells by increasing fatty acid oxidation via protein kinase A. J Biol Chem. 2001; 276:25096-25100.

25. Shao JS, Cai J, Towler DA. Molecular mechanisms of vascular calcification: Lessons learned from the aorta. Arterioscler Thromb Vasc Biol. 2006;26:1423-1430.

26. Foley RN, Parfrey PS, Sarnak MJ. Epidemiology of cardiovascular disease in chronic renal disease. J Am Soc Nephrol. 1998;9:S16-S23.

27. Iribarren C, Sidney S, Sternfeld B, Browner WS. Calcification of the aortic arch: Risk factors and association with coronary heart disease, stroke, and peripheral vascular disease. JAMA. 2000;283:2810-2815.

28. Keelan PC, Bielak LF, Ashai K, et al. Long-term prognostic value of coronary calcification detected by electron-beam computed tomography in patients undergoing coronary angiography. Circulation. 2001;104: 412-417.

29. Civilibal M, Caliskan S, Adaletli I, et al. Coronary artery calcifications in children with end-stage renal disease. Pediatr Nephrol. 2006;21: $1426-1433$.

30. Jono S, Shioi A, Ikari Y, Nishizawa Y. Vascular calcification in chronic kidney disease. J Bone Miner Metab. 2006;24:176-181.

31. Wada T, McKee MD, Steitz S, Giachelli CM. Calcification of vascular smooth muscle cell cultures: Inhibition by osteopontin. Circ Res. 1999; 84:166-178.

32. Shioi A, Nishizawa Y. Vascular calcification: Osteogenic transformation of vascular smooth muscle cells. J Oral Biosci. 2010;52:26-32.

33. Parhami F, Basseri B, Hwang J, Tintut Y, Demer LL. High-density lipoprotein regulates calcification of vascular cellsane. Circ Res. 2002; 91:570-576.

34. Vattikuti R, Towler DA. Osteogenic regulation of vascular calcification: An early perspective. Am J Physiol Endocrinol Metab. 2004;286: E686-E696.

35. Venturinelli ML, Hovnan A, Soeiro A de M, et al. Platelet activation in different clinical forms of the coronary artery disease (role of P-selectin and others platelet markers in stable and unstable angina). Arq Bras Cardiol. 2006;87:446-450. Spanish.

36. Bostrom K, Watson KE, Horn S, et al. Bone morphogenetic protein expression in human atherosclerotic lesions. J Clin Invest. 1993;91: 1800-1809.

37. Hunt JL, Fairman R, Mitchell ME, et al. Bone formation in carotid plaques: A clinicopathological study. Stroke. 2002;33:1214-1219.

38. Virmani R, Burke AP, Farb A. Plaque morphology in sudden coronary death. Cardiologia. 1998;43:267-271.

39. Richardson PD, Davies MJ, Born GV. Influence of plaque configuration and stress distribution on fissuring of coronary atherosclerotic plaques. Lancet. 1989;2:941-944.

40. Ge J, Chirillo F, Schwedtmann J, et al. Screening of ruptured plaques in patients with coronary artery disease by intravascular ultrasound. Heart. 1999;81:621-627. 
41. Colombo A, Anzuini A. Intravascular ultrasound-guided elective stent implantation in calcified coronary lesions. A picture is worth more than a thousand words (sometimes!). Eur Heart J. 1998;19:1127-1129.

42. Mintz GS, Dussaillant GR, Wong SC. Rotational atherectomy followed by adjunct stents: The preferred therapy for calcified lesions in larger vessels? Circulation. 1995;92:I329.

43. Hoffmann R. Treatment of calcified coronar y lesions with PalmazSchatz stents: An intravascular ultrasound study. Eur Heart J. 1998;19: 1224-1231.

44. Lehto S, Niskanen L, Suhonen M, et al. Medial artery calcification: A neglected harbinger of cardiovascular complications in non-insulindependent diabetes mellitus. Arterioscler Thromb Vasc Biol. 1996;16: 978-983.

45. Speer MY, Giachelli CM. Regulation of cardiovascular calcification. Cardiovasc Pathol. 2004;13:63-70.

46. Mathur RV, Shortland JR, el-Nahas AM. Calciphylaxis. Postgrad Med J. 2001;77:557-561.

47. Serrano CV Jr, Santos ES, Mangione JA, et al. Enhanced inflammatory response following coronary stent implantation in stable angina patients. Int J Cardiol. 2007;118:69-75.

48. Pugliese F, Meijboom WB, Ligthart J, et al. Parameters for coronary plaque vulnerability assessed with multidetector computed tomography and intracoronary ultrasound correlation. J Cardiovasc Med. 2009;10 821-826.

49. Murray SW. Contemporary coronary imaging from patient to plaque Part 1: IVUS-derived virtual histology. Br J Cardiol. 2010;17:129-132.

50. Rumberger JA. Coronary artery calcium area by electron-beam computed tomography and coronary atherosclerotic plaque area. A histopathologic correlative study. Circulation. 1995;92:2157-2162.

51. Farzaneh-Far A, Proudfoot D, Shanahan C, Weissberg PL. Vascular and valvar calcification: Recent advances. Heart. 2001;85:13-17.

52. Mittal TK, Barbir M, Rubens M. Role of computed tomography in risk assessment for coronary heart disease. Postgrad Med J. 2006;82: 664-671.

53. Van Werkhoven JM, Bax JJ, Nucifora G, et al. The value of multi-slicecomputed tomography coronary angiography for risk stratification. J Nucl Cardiol. 2009;16:970-980.
54. Genders TS, Pugliese F, Mollet NR, et al. Incremental value of the CT coronary calcium score for the prediction of coronary artery disease. Eur Radiol. 2010;20:2331-2340.

55. Van Werkhoven JM, Schuijf JD, Gaemperli O, et al. Incremental prognostic value of multi-slice computed tomography coronary angiography over coronary artery calcium scoring in patients with suspected coronary artery disease. Eur Heart J. 2009;30:2622-2629.

56. Ergün E, Koşar P, Oztürk C, Başbay E, Koç F, Koşar U. Prevalence and extent of coronary artery disease determined by 64 -slice CTA in patients with zero coronary calcium score. Int J Cardiovasc Imaging. August 24, 2010. [Epub ahead of print].

57. Agatstone AS, Janowitz WR, Kaplan G, et al. Electron beam CT coronary calcium predicts future coronary events. Circulation. 1996;94:I360.

58. Raggi P, Shaw LJ, Berman DS, Callister TQ. Prognostic value of coronary artery calcium screening in subjects with and without diabetes. J Am Coll Cardiol. 2004;43:1663-1669.

59. Detrano R. Prognostic value of coronary calcification and angiographic stenoses in patients undergoing coronary angiography. J Am Coll Cardiol. 1996;27:285-290.

60. O’Rourke RA, Brundage BH, Froelicher VF, et al. American College of Cardiology/American Heart Association Expert Consensus document on electron-beam computed tomography for the diagnosis and prognosis of coronary artery disease. Circulation. 2000;102:126-140.

61. Greenland P, Bonow RO, Brundage BH, et al. ACCF/AHA 2007 clinical expert consensus document on coronary artery calcium scoring by computed tomography in global cardiovascular risk assessment and in evaluation of patients with chest pain: A report of the American College of Cardiology Foundation Clinical Expert Consensus Task Force (ACCF/AHA Writing Committee to Update the 2000 Expert Consensus Document on Electron Beam Computed Tomography) developed in collaboration with the Society of Atherosclerosis Imaging and Prevention and the Society of Cardiovascular Computed Tomography. J Am Coll Cardiol. 2007;49:378-402.
Vascular Health and Risk Management

\section{Publish your work in this journal}

Vascular Health and Risk Management is an international, peer-reviewed journal of therapeutics and risk management, focusing on concise rapid reporting of clinical studies on the processes involved in the maintenance of vascular health; the monitoring, prevention and treatment of vascular disease and its sequelae; and the involvement of

\section{Dovepress}

metabolic disorders, particularly diabetes. This journal is indexed on PubMed Central and MedLine. The manuscript management system is completely online and includes a very quick and fair peer-review system, which is all easy to use. Visit http://www.dovepress.com/ testimonials.php to read real quotes from published authors. 